\title{
DAILY DISTRIBUTION OF UV-INDEX IN BELO HORIZONTE (BRAZIL) AND THE SHADOW RULE
}

\author{
Abel A. Silva \\ Recebido em 13 março, 2009 / Aceito em 14 setembro, 2009 \\ Received on March 13, 2009 / Accepted on September 14, 2009
}

\begin{abstract}
According to the Shadow Rule (SR), an individual can control the time of exposure to the Sun observing the body's shadow length on a horizontal surface. Although a simple rule, the SR depends primarily on the ozone column (03) amount, which can complicate the application of this rule in scenarios of lower 03 amounts like those in the low latitudes of Southern Hemisphere. The SR by itself can be confusing and impractical for application, as the shadow length can be of uneasy grasp and high uncertainty use unless one is equipped with calculator and ruler. Using the daily distribution of erythemal dose rates in Belo Horizonte $\left(\mathrm{BH}, 19.92^{\circ} \mathrm{S}\right.$, $43.94^{\circ} \mathrm{W}, 858 \mathrm{~m}$ asl, $331 \mathrm{~km}^{2}$, Brazil) for a period of 22 months, this work shows that a warning on time for solar exposure can be a safer, more efficient and more practical procedure in terms of creating a culture of casual exposure to the Sun than the use of the SR. For tropical and equatorial Brazilian sites, the diurnal interval for the avoidance of dangerous solar incidence of ultraviolet radiation is that between 2.5 hours after sunrise and 2.5 hours before sunset.
\end{abstract}

Keywords: solar ultraviolet radiation, shadow rule, UV-Index.

RESUMO. A Regra da Sombra (RS) é um princípio que visa orientar as pessoas sobre o momento de evitar a exposição direta ao Sol a partir do comprimento da sombra gerada pelo corpo sobre uma superfície plana. Embora simples, a RS depende de fatores atmosféricos como o montante de ozônio, o que complica a sua aplicabilidade em regiões onde há tipicamente montantes menores desse gás como nas baixas latitudes do hemisfério Sul. A RS por si só pode ser confusa e de difícil aplicação, uma vez que o comprimento da sombra no momento de se evitar o Sol pode ter um valor de difícil assimilação e mensuração sem a ajuda de algum instrumental. Neste artigo, como uma atitude em favor de uma cultura de menor exposição ao Sol, mostra-se que é melhor utilizar a hora local como referência em vez da RS baseando-se em um conjunto de 22 meses de medidas de taxa de dose eritematosa em Belo Horizonte (BH, 19,92 $\mathrm{S}, 43,94^{\circ} 0,858 \mathrm{~m}, 331 \mathrm{~km}^{2}$, Brasil). Assim, para 0 território brasileiro o intervalo de tempo para se evitar o Sol é aquele compreendido entre 2,5 horas após o Sol nascer e 2,5 horas antes do Sol se pôr.

Palavras-chave: radiação solar ultravioleta, Regra da Sombra, índice UV. 


\section{INTRODUCTION}

A multitude of beneficial and harmful effects on human beings can arise from the exposure to the ultraviolet radiation (UVR) (WHO, 1994; Godar, 2005). Benefits like vitamin D synthesis and harms like skin cancer have produced conflicting ideas regarding the exposure to the Sun (Tangpricha et al., 2004; Berwick \& Kesler, 2005; Wolpowitz \& Gilchrest, 2006). In addition, many segments of the human culture have clearly a biased tendency for excessive solar exposure. In fact, people generally believe that the Sun makes them happier and more attractive. However that may be true, there is no doubt on the deleterious effects of overexposure habits.

It has been more than a decade since the start of the first large campaigns advising people about the dangers of solar overexposure (WHO, 1994). Many studies have been conducted assessing the outcomes regarding the adoption of protective attitudes like using sun-block cloths, sunscreens, hats, sunglasses and even personal dosimeters (Kullvanijaya \& Lim, 2005; Lautenschlager et al., 2007; Carli et al., 2008). In spite of being welcome among people, yet such attitudes have not been able to produce a decrease in the incidence of the harmful biological effects (Dobbinson et al., 2008). One of the best explanations for that remains in the way people still deal with the Sun. More than ever, people keep overexposing themselves daily and, unfortunately, contrary to what would be aimed, some protective attitudes have indeed worked as a stimulus for people to stay longer outdoors in the Sun, based on the misleading idea they are protected (BenvenutoAndrade et al., 2005; Weinstock, 2008). Perhaps the basic message forwarded by campaigns against overexposure has not achieved its main goal: the protective attitudes aim at reducing the erythemal dose absorbed by individuals instead of providing them with a tool to stay longer in the Sun.

The avoidance of persistent solar exposure during the largest part of the diurnal period is always advisable, although arguments for controlled exposure find support in the need for good levels of vitamin D concentration in the serum (Wolpowitz \& Gilchrest, 2006). Some procedures have been proposed aiming at simple but efficient attitudes to avoid high solar UVR incidence: The Shadow Rule (SR) is one of them (Halloway, 1992). It states that an individual should avoid staying in the Sun if the body's shadow on a horizontal surface is smaller than a certain length, meaning that the Sun is going higher in the sky to produce UV-Index (UVI) values larger than 2, thereby out of the low range UVI where no protection is needed (WHO, 2002). Mathematically, the SR regards the ratio of the shadow length to the body's height or, in equivalence, the tangent of the solar zenith angle (SZA). Some authors (Downham, 1998; Sliney \& Wengraitis, 2006) have proposed the shadow length to be equal to the body's height (SZA = $45^{\circ}$ or ratio 1) for the SR application. Maybe this works well for the typical ozone column (03) amounts in the middle and high latitudes of Northern Hemisphere (Bojkov et al., 1990). But it fails if applied to the low latitudes (equatorial and tropical zones) of Southern Hemisphere because much lower 03 amounts are found in that region, producing an increment in the solar UVR incidence. A comparison between hemispheres shows on average 15-45\% more 03 for such zones in the Northern Hemisphere (Whitten \& Prasad, 1985). It is also noteworthy that such an increment in the UVR incidence receives additionally a contribution from the shortest Earth-Sun distance occurring during Southern Hemisphere summer. Thus the sensitive point using the SR in the low latitudes of Southern Hemisphere is that the higher incidence of UVR implies shadow lengths whose values are not as easy to grasp as that one for SZA of $45^{\circ}$, making more difficult the applicability of the rule.

Additional questioning can essentially be set against the applicability of the SR: (i) This rule has a critical dependence on a true horizontal surface on which the shadow must lie, representing a non-trivial aspect to be ensured by one intending to use it; (ii), Hardly one would be skilled with the ability to release a low uncertainty measurement of his or her shadow length without a ruler; (iii) The daily 03 amount variation introduces large uncertainties in the use of the SR, and (iv) a cloudy sky makes impossible the application of the SR, although the UVR incidence can yet be harmful (Silva et al., 2008).

In spite of its mathematical interpretation, the SR resembles much more an approximation in terms of applicability than an exact rule. Its main goal of reminding people when they should get out of the Sun strongly depends on the local amount of 03 besides requiring some sort of skill from the public to whom it is aimed. Therefore, a proposal for warning people about the period of time they should avoid being in the Sun seems to work better than this rule, as time along the day is by far much easier to obtain than the measurement of the shadow length on the ground, making the attitude of protection against overexposure to the Sun an easy daily routine for all. This work discusses such a proposal on the basis of 22 months of erythemal dose rate (EDR) measurements made in a tropical Brazilian site with application for the whole country.

\section{MATERIAL AND METHODS}

A Biometer Solar Light (Solar Light Co., Inc., Glenside, USA) model 501A, serial number 9007, has been operating in Belo 


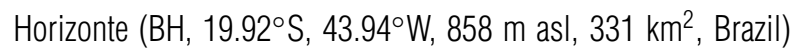
since 2005 set up by the Laboratório de Luz Ultravioleta (LLUV, www.dfq.pucminas.br/PUV/index.html). The site is an urban, tropical Brazilian city with significant commercial and industrial activities. The Biometer measures the erythemal dose rates (EDR) of the UVR erythemally weighted by an action spectrum similar to that one in the work by McKinlay \& Diffey (1987). Being calibrated each 12 months of use, the Biometer is maintained in accordance with manufacturer's recommendation, operates at a constant temperature of $25^{\circ} \mathrm{C}$ and its measurements are treated for cosine error. According to Hülsen \& Gröbner (2007), well-maintained Biometers' measurements have uncertainties within the range 3.9$5.6 \%(1 \sigma)$. Temporal uncertainties in measurements are kept within 10 seconds based on automatic adjustment to atomic clock references via Internet. In fact, the Biometer makes timeintegrated (5-6 minutes in the present study) measurements of the erythemal dose incidence, which divided by the period of measurement produces an average value assumed as the Biometer's EDR measurement for that time period.

The UVR incidence for a given site on the Earth's surface depends primarily on the SZA, 03 , clouds, aerosols, ground albedo and the site's elevation. The Ozone Monitoring Instrument (OMI, http://avdc.gsfc.nasa.gov/index.php?site=1593048672\&id=28 for data regarding BH) (Schoeberl et al., 2004) is an experiment flying on board the Aura satellite since 2004 whose polar orbiting around the Earth yields noon-synchronized overpass measurements of 03 , reflectivity $\left(\mathrm{R}_{\mathrm{PC}}\right)$ and aerosol index (Al) within a 13 $\times 24 \mathrm{~km}$ grid $\left(312 \mathrm{~km}^{2}\right)$ once or twice a day. The reflectivity is the percent of radiation at $360 \mathrm{~nm}$ backscattered to the space by the Earth's surface (ground and water reservoirs) and the atmosphere (clouds, water haze, and aerosols) (Herman et al., 2001). Clouds are the most important UV reflector for snow-free surfaces. Hence the reflectivity obtained from $\mathrm{OMI}$ is also called the partly cloud reflectivity $R_{P C}$ since it varies from 8 to $80 \%$ with the cloud cover from 0 to $100 \%$. The aerosol index is a measurement of the wavelength-dependent reduction of Rayleigh scattered radiance by aerosol absorption relative to pure Rayleigh atmosphere (Hsu et al., 1999). It is positive for absorbing aerosols and negative for non-absorbing ones, although absorbing aerosols near the Earth's surface can produce erroneous negative values. A dependence on the altitude the aerosol layer is set increases the uncertainty in the Al values.

Because clouds have a crucial influence on the UVR incidence, a Total Sky Imager (TSI) 440A (Yankee Environmental Systems, Inc., Turners Falls, USA) was set up beside the Biometer. The TSI releases 1 sky image per minute, which quantifies the cloud cover percentages in the sky after treating the image by a computer routine. In situations where the TSI was out of operation, visual surveillance of the sky and the EDR distribution along the day were used for qualifying a day as cloudless or not.

Thus on the basis of EDR measurements for a period of 22 months (November/2005-August/2006 and September/2007August/2008), daily distributions of UVI in BH are analyzed in terms of time and intensity distributions with emphasis on the EDR meteorological and seasonal dependence (especially some cloud effects on the measurements), leading to the empirical determination of an average daily-time period for safe solar exposure. A generalization for the whole Brazilian territory is obtained using the Tropospheric Ultraviolet Visible (TUV) model version 4.4 (http://cprm.acd.ucar.edu/Models/TUV) (den Outer et al., 2005) that calculates the erythemally weighted UVR incidence from the Delta-Eddington 2-stream radiative transfer method for the U.S. Standard Atmosphere. Based on the analysis of such measurements, a wide discussion is developed regarding the application of the SR to the Brazilian sites.

\section{RESULTS AND DISCUSSION}

The OMI monthly average values of $03, \mathrm{R}_{\mathrm{PC}}$ and $\mathrm{Al}$ for $\mathrm{BH}$ obtained for the period September/2004-August/2008 are shown in Figure 1. With minimum and maximum values for 03 occurring typically in May and October, respectively, the site has also a rainy season from November to April, indicated by the highest $R_{P C}$ and lowest Al values, and a dry season from May to October indicated by the lowest $\mathrm{R}_{\mathrm{PC}}$ and highest Al values. Taking two cloudless days (Identified as such through the TSI images) - 0ctober 5, 2007 with one of the highest 03 amounts (296.6 Dobson Units (DU)) and May 23, 2008 with one of the lowest 03 amounts (246.2 DU) - and plotting their corresponding EDR incidences, we find that low range UVI (UVI $\leq 2$ corresponding to EDR $<$ $0.0625 \mathrm{~W} / \mathrm{m}^{2}$ ) only occurs for SZA of $54^{\circ}$ or larger as shown in Figure 2. The low range UVI corresponds to a safe solar exposure in terms of fair skinned people being free of sunburn, but for $45^{\circ}$ SZA the UVI is in the moderate and high ranges. Obviously, the SR must be adapted for a scenario of lower 03 amounts. In this case, the shadow length cast by the person on a horizontal surface should be 1.4 and 1.7 the person's height for SZA of $54^{\circ}$ and $59^{\circ}$, respectively. There is no doubt that these values turn the applicability of the SR much more difficult than the proposal of $45^{\circ}$ SZA (person's height equals shadow length), because such quantities are of uneasy grasp and high uncertainty application for one not equipped with a ruler and a pocket calculator, what is totally contradictory to a simple and practical application of the rule. 

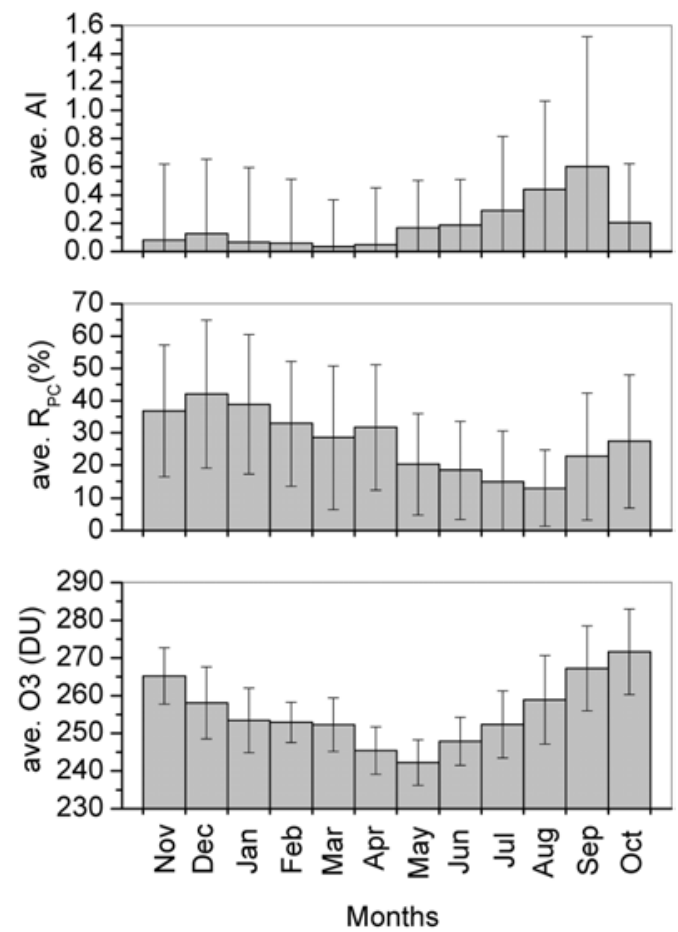

Figure 1 - Monthly average values of (top) Al, (middle) $R_{P C}$ and (bottom) 03 from OMI for BH in the period September/2004-August/2008. Bars are 1 standard deviation (sd).

The period of time those two days were under EDR incidence in the low range UVI varies from 2.2 to 2.6 hours early in the morning after sunrise and late afternoon before the sunset as they were cloudless days. Additionally, the lack of clouds also closely yields both noontimes of highest EDR values and symmetrical daily EDR distributions. Nonetheless, clouds are the main atmospheric agent in the modulation of UVR incidence (McKenzie et al., 2007), producing the quickest and almost highest changes in EDR in addition to longer diurnal low range UVI intervals. Furthermore, they cause a wide drift in the occurrence time for daily maximum EDR around noon. Figure 3 depicts such an effect where the largest presence of clouds in the rainy season matches the widest drift in the occurrence time for the daily maximum EDR. Figure 4 shows the daily maximum EDR for the period, and again the high variability set by cloudiness in the EDR incidence is observed during the rainy season months. Typical maximum EDR amounts for cloudless scenarios in $\mathrm{BH}$ are in the range from $0.350 \mathrm{~W} / \mathrm{m}^{2}$ (summer) to $0.160 \mathrm{~W} / \mathrm{m}^{2}$ (winter). Remarkably, cloudy events in March/2006 points out that clouds produce not only attenuation, but also enhancement as both the lowest and the highest EDR values in the whole period of investigation occurred in that month with the latter reaching $0.484 \mathrm{~W} / \mathrm{m}^{2}$. EDR distributions for these two days are depicted in Figure 5. Note that, in spite of being a day with similar SZA distribution and lower 03 amount in relation to March 10, March 16 shows quite low EDR incidences due to attenuation by clouds.

Thus the EDR incidence experiments daily variations owing to different meteorological conditions. Monthly average daily EDR distributions in the period September/2007-August/2008 are shown in Figure 6 . An equivalent analysis for the period November/2005-August/2006 is found in Silva \& Gabrich (2007). Notably, both variability and uncertainties in EDR are significantly higher in the rainy season months than in the dry ones. However, the distributions in Figure 6 shows that on average the low range UVI values for all months are approximately within 2.6 hours in early morning and late afternoon of the diurnal period. Therefore, a daily distribution of UVI in terms of time interval under a given UVI range will give both the safe and unsafe time for solar exposure. Figure 7 depicts the hourly distribution of daily UVI in $\mathrm{BH}$ for the whole period of investigation. The average amount of diurnal hours within low range UVI is $5.3 \pm 1.0 \mathrm{hr}$ per day, which can reasonably be split into 2.6 hours after sunrise and 2.6 hours before sunset. For the rest of the day the occurrence of low range UVI or other higher ranges will depend on the season (SZA distributions), 03, clouds and aerosols too.

Therefore, the applicability of the SR to BH would bring concern regarding a safe sunbath, as this rule shows itself unpractical and of doubtful rightness owing to its strong dependence on the 03 amount. Additionally, during episodes of cloudy skies the application of the rule could become impossible, although the EDR incidence not necessarily is within the low range UVI (Silva et al., 2008). Taking into account both the closer to equator the higher the UVR incidence and that the 03 amounts for Brazilian sites within the tropics is quite similar to those for $\mathrm{BH}$ (Long et al., 1996; Silva, 2007), it is quite reasonable to affirm that the SR would not work properly in any other tropical latitude of the country either. Even in southern Brazil (latitude $\approx 30^{\circ}$ ), where 03 amounts are typically a few percent higher than that in the tropics, the application of the SR would also be unsuccessful based on the results shown by Palancar \& Toselli (2002) who have measured EDR values in the moderate range UVI during winter noon in Córdoba (31.40 S, Argentina) with, naturally, SZA distribution angles larger than $45^{\circ}$.

The TUV model can support the affirmation made in the last paragraph using two Brazilian sites in the extremes of the country: Natal (Na, $5.79^{\circ} \mathrm{S}, 35.21^{\circ} \mathrm{W}, 30 \mathrm{~m}$ asl, $170 \mathrm{~km}^{2}$ ) and Porto Alegre (PA, $30.03^{\circ} \mathrm{S}, 51.23^{\circ} \mathrm{W}, 3 \mathrm{~m}$ asl, $497 \mathrm{~km}^{2}$ ). For it, first, the model is applied to $\mathrm{BH}$ on June 14,2008 , which was a cloudless day with 03 amount of $242.7 \mathrm{DU}$ according to $\mathrm{OMI}$. 


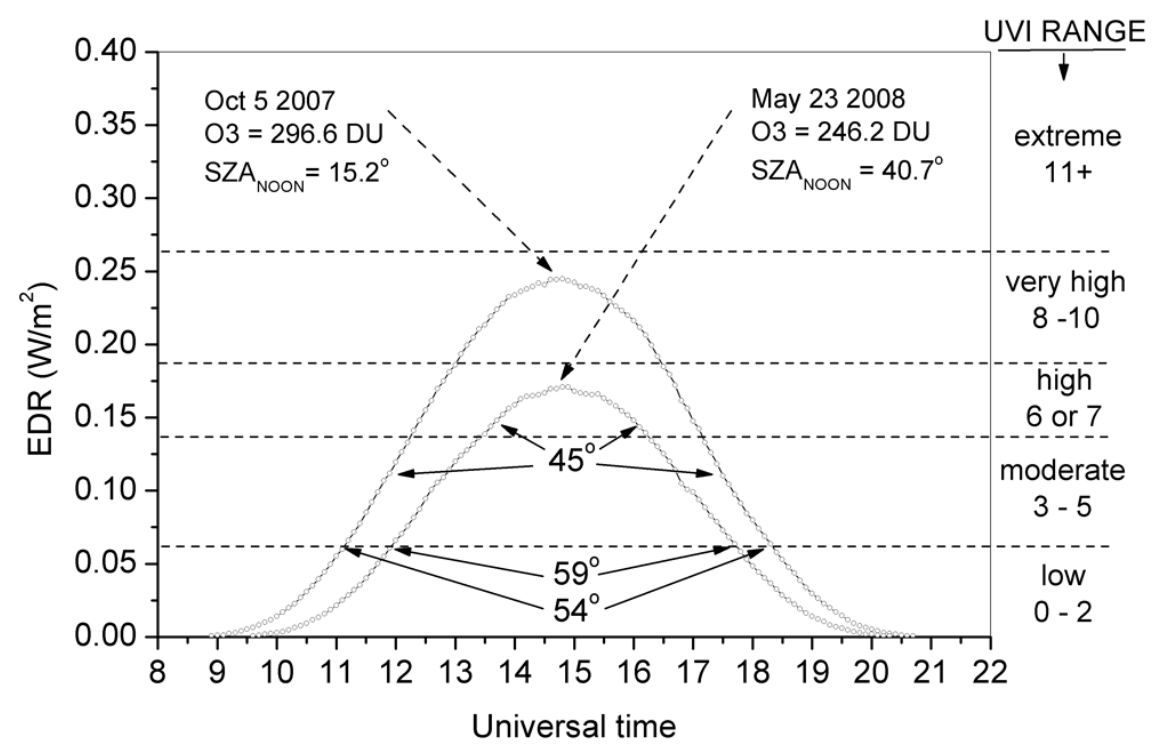

Figure 2 - Erythemal dose rates in BH for days with low and high 03 amounts. Central settled values in degrees represent the SZA for the EDR measurements indicated by the arrows. SZA NOON represents SZA at noon, and the horizontal dashed lines limit the UVI ranges shown on the right margin.

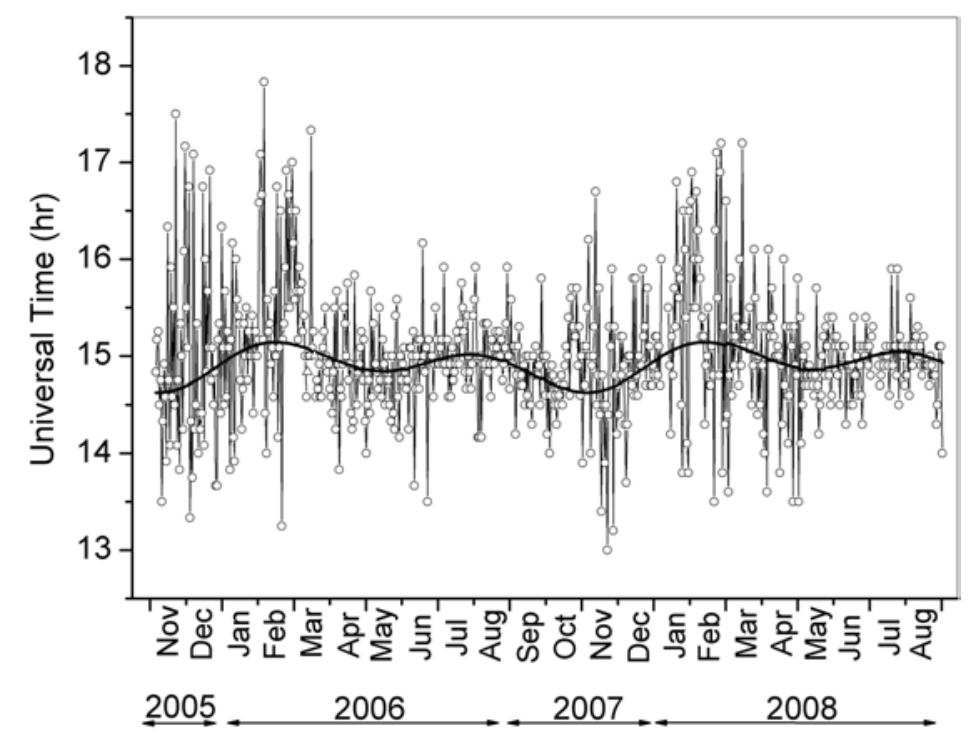

Figure 3 - Circles refer to the occurrence time of daily maximum EDR in BH. The solid line depicts noontime.

Since no information on the size distribution and content of aerosols or content of other trace gases than ozone in the atmosphere is available, it is assumed a continental atmosphere with standard parameters optimized for erythemal dose calculation in the TUV model. In addition, BH and the other two sites are urban capitals with their territorial area typically covered by concrete and asphalt that suggests a surface albedo of about 0.04 (Blumthaler \& Ambach, 1988). In order to obtain the aero- sol optical depth (AOD) for the BH atmosphere that day, an AOD value was adjusted to the TUV model routine to produce EDR values that matched the measured ones: an AOD value of 0.379 at $550 \mathrm{~nm}$ was found. Second, the TUV model was applied to the other two sites with their typical 03 amounts (266 DU for $\mathrm{Na}$ and $283 \mathrm{DU}$ for PA), which are averages drawn from the Total Ozone Mapping Spectrometer (TOMS) data for the 1978-2001 period (Silva, 2007). Figure 8 depicts the EDR values generated 


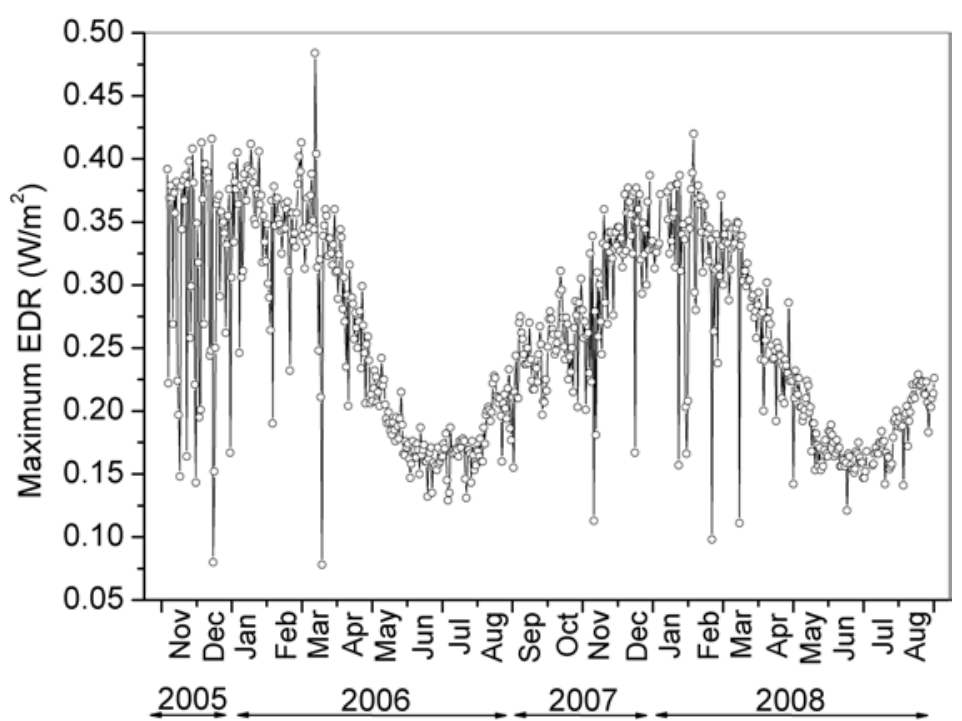

Figure 4 - Daily maximum EDR values for $\mathrm{BH}$.

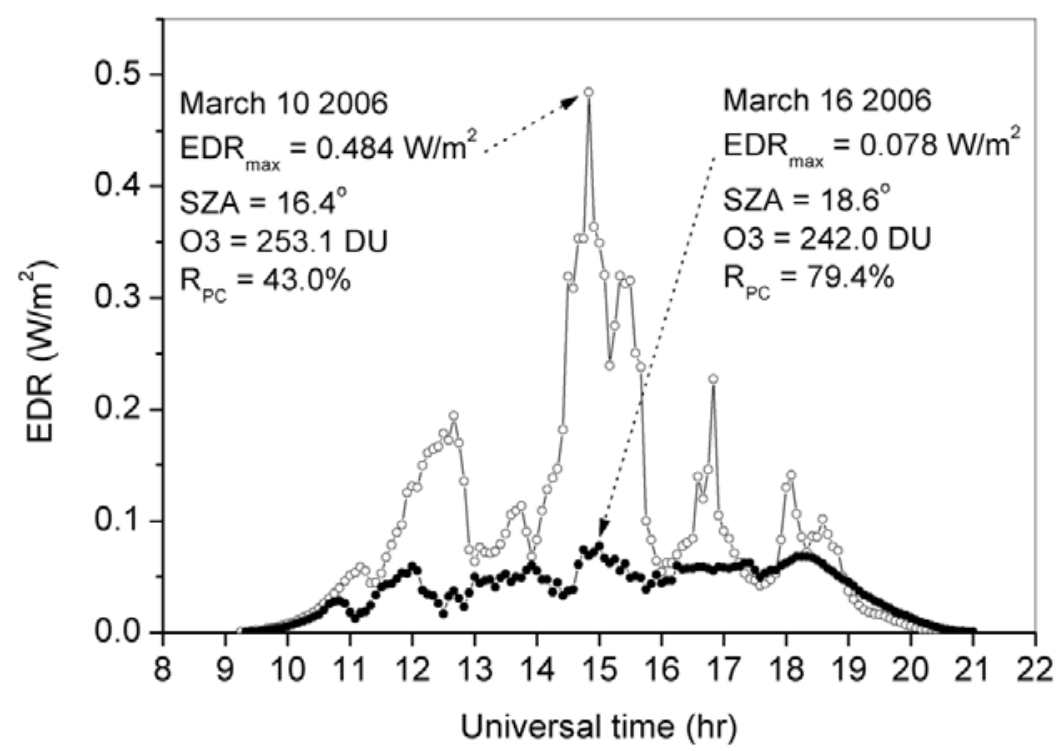

Figure 5 - EDR distributions on March 10 (open circles) and March 16 (closed circles), 2006. Daily maximum EDR for each of these days is shown besides the corresponding SZA and OMI values of 03 and RPC.

by TUV for the three sites and the EDR measurements for $\mathrm{BH}$. The intersections of the EDR curves with the horizontal dashed line limiting the low range UVI zone have side-figures representing the SZA at those moments. In all cases, from north to south Brazil, the use of the SR would bring the same difficulties as those for $\mathrm{BH}$, as suggested by the minimum SZA values needed for the low range UVI. A period of at least 2.4 hours after sunrise and before sunset provides safe solar exposure in $\mathrm{Na}$, while a larger period of 3.7 hours is for PA. Such a difference comes mainly from both the SZA distribution for PA, whose latitude is higher than the Tropic of Capricorn, and the larger 03 amounts for PA.

Using the average between $\mathrm{BH}$ and $\mathrm{Na}$ for practical application among people, an average value of 2.5 hours after sunrise and before sunset for safe solar exposure would attend all Brazilian latitudes. On the other hand, the site's elevation is a parameter to which the EDR incidence also depends on. However, a simulation by TUV shows that if $\mathrm{BH}$ were 1,000 meters higher the EDR incidence augmentation would be by $4.9 \%$ with a reduc- 

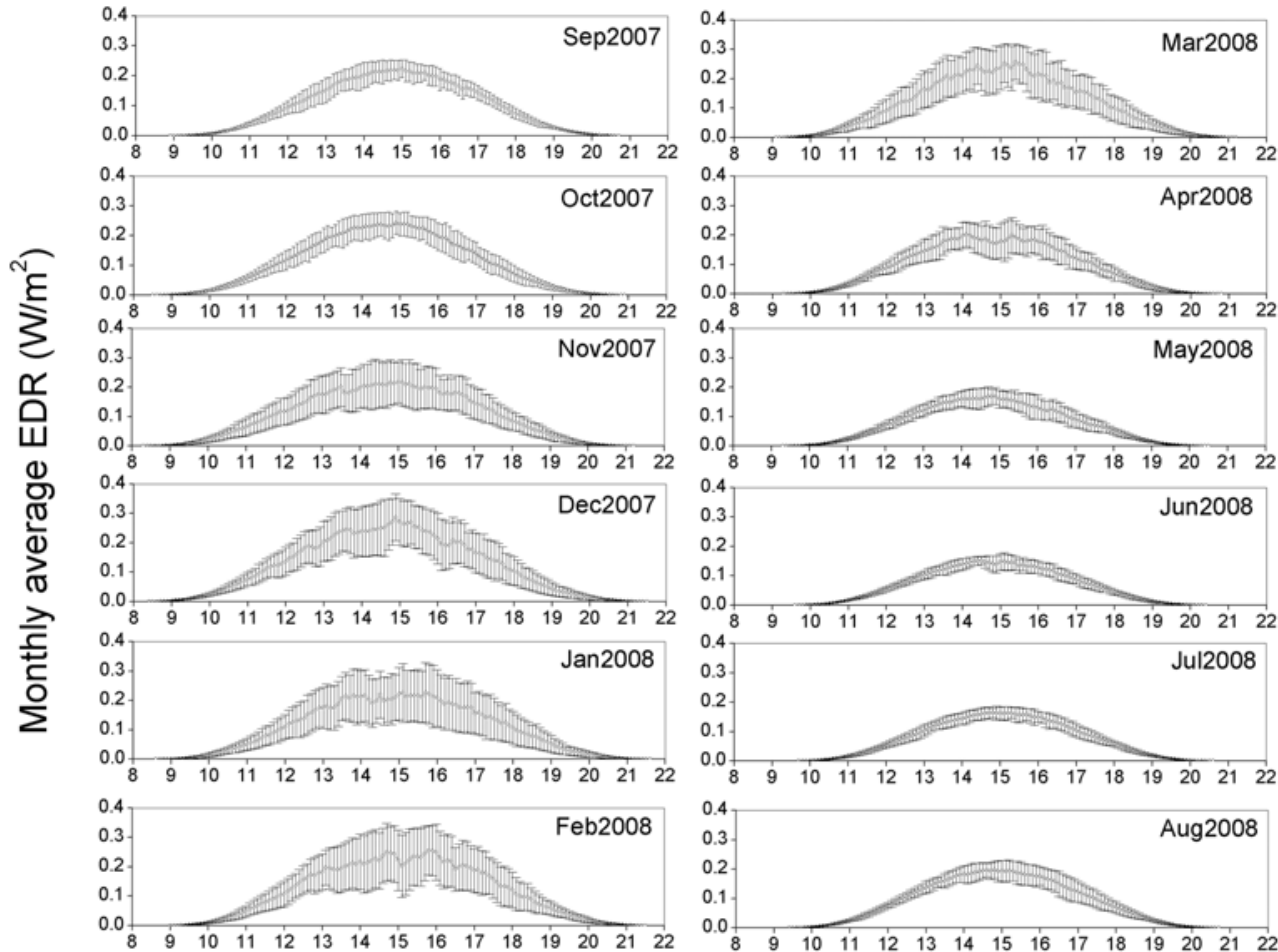

Universal Time (hr)

Figure 6 - Monthly average daily EDR distributions for BH. Bars are $1 \mathrm{sd}$

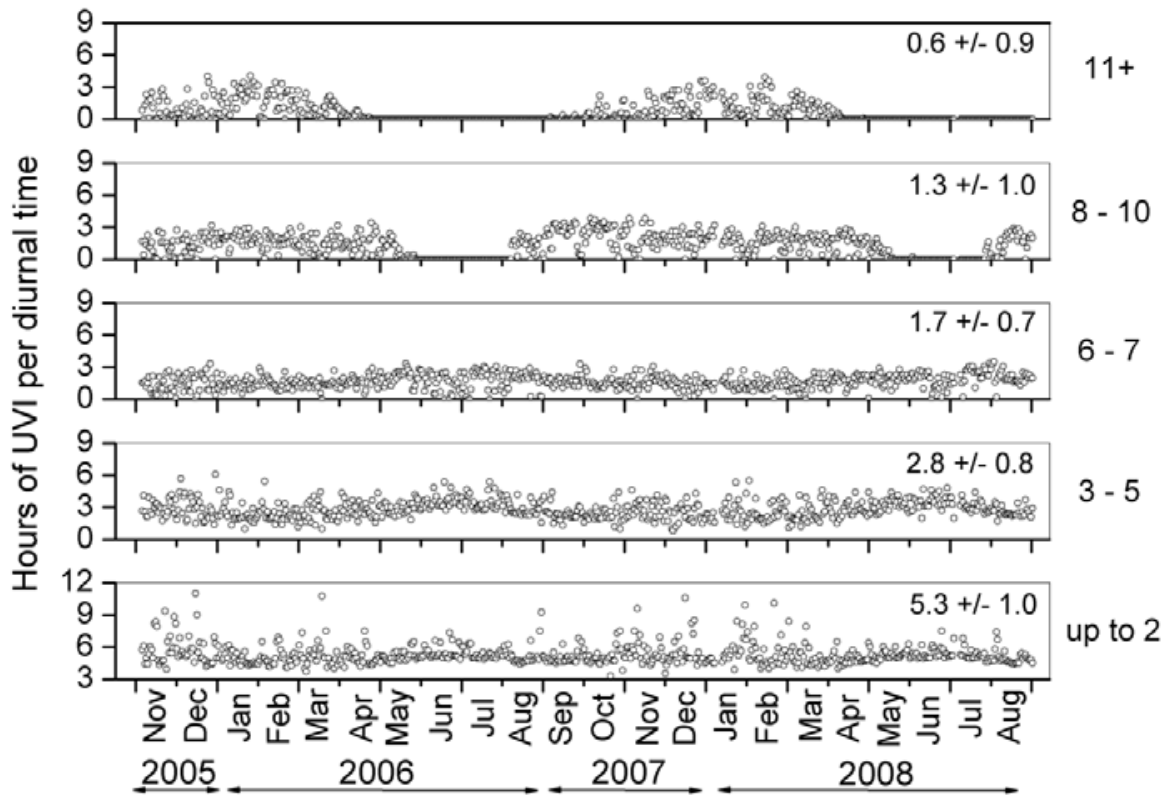

Figure 7 - Daily distributions of UVI in the diurnal period in BH. Both UVI ranges and the average amount of hours within each range are shown on the right side. Uncertainties are $1 \mathrm{sd}$. 


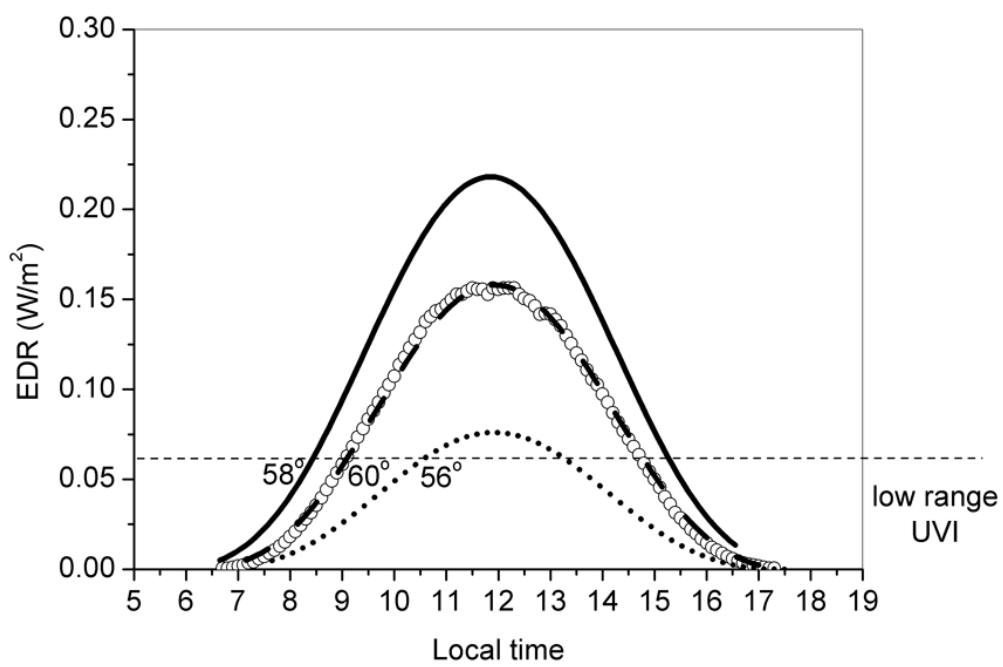

Figure 8 - EDR incidences calculated by TUV for the Brazilian sites Na (solid line), BH (dashed line) and PA (dotted line) on June 14, 2008. The line of circles matching the TUV dashed line represents EDR measurements for $\mathrm{BH}$. The intersections between EDR curves and the horizontal dashed line are accompanied by figures representing the SZA values at those moments.

tion of 3 minutes in the 2.5-hour period proposed. Since most of Brazilian sites are quite below $1000 \mathrm{~m}$, such a minute-time reduction can be neglected since it doesn't represent a significant threat to people exposed.

The statement of a daily period within the low range UVI as a safe time for solar exposure in terms of avoiding sunburn could bring some criticism out regarding the eventual lack of vitamin D synthesis during such a period. However, people are used to exposing themselves to the Sun casually in several daily activities, even when exposure is not wanted or desired (Diffey, 2006; Gillie, 2006). In a country like Brazil, generously served with solar radiation all year long, exposure will happen inevitably and hardly there will be inefficiency or miss of opportunity for vitamin D synthesis (Silva, 2008). In fact, a greater concern is to develop a rationale for solar exposure in a way that people would grasp at the benefits and avoid, or minimize, the chances for harm. In this sense, transmitting to the public the notion that they only would have safe exposure for a couple of hours (2.5 hours for Brazilian latitudes) at the beginning and at the end of the diurnal period (Out of which they are not completely protect no matter if under protective attitudes) would give them a better understanding to improve their habits in relation to the Sun. Time along the day is something quite easier to be obtained than the perception of the shadow length on the ground as proposed by the SR with its strong dependence, to say the least, on atmospheric parameters that are not at all under the monitoring of people in casual life.

\section{CONCLUSION}

In this work, the UVR incidence at an urban, tropical Brazilian site was erythemally measured and investigated, aiming at providing support for a proposal to limit people's solar exposure based on time instead of the SR, which fails as a casual practice among people in the Southern Hemisphere tropics mainly owing to the typical lower 03 amounts in that region. The timely unpredictability of daily 03 amounts for people in general associated with the effect of clouds on the UVR brings a high-risk aspect to the applicability of the SR regarding safe solar exposure.

The advantage of a time-limitation warning instead of the SR is that people would easily understand and use it, without any need of other knowledge but the time, which can be easily obtained. The interval of 2.5 hours after sunrise and before sunset means that, in $\mathrm{BH}$, any exposure to the Sun from 9 a.m. to 3 p.m. (local standard time, winter) and from 8 a.m. to 4 p.m. (summer) raises the chances for sunburn and other UVR harmful effects and should be avoided. An explicit and emphatic message of such a time-limitation interval added to the already existing protective attitudes could significantly mitigate the habits of overexposure to the Sun. Such a concept can readily be extended to the whole country.

\section{ACKNOWLEDGEMENTS}

I would like to thank the Fundação de Amparo à Pesquisa do Estado de Minas Gerais (FAPEMIG) and the Conselho Nacional de Desenvolvimento Científico e Tecnológico (CNPq) for grants. 


\section{REFERENCES}

BENVENUTO-ANDRADE C, ZEN B, FONSECA G, DE VILLA D \& CESTARI T. 2005. Sun exposure and sun protection habits among high-school adolescents in Porto Alegre, Brazil. Photochem. Photobiol., 81: 630635 .

BERWICK M \& KESLER D. 2005. Ultraviolet radiation exposure, vitamin D, and cancer. Photochem. Photobiol., 81: 1261-1266.

BLUMTHALER M \& AMBACH W. 1988. Solar UVB-albedo of various surfaces. Photochem. Photobiol., 48: 85-88.

BOJKOV R, BISHOP L, HILL WJ, REINSEL GC \& TIAO GC. 1990. A statistical trend analysis of revised Dobson total ozone data over the northern hemisphere. J. Geophys. Res., 95: 9785-9807.

CARLI P, CROCETTI E, CHIARUGI A, SALVINI C, NARDINI P, ZIPOLI G \& SIMEONE E. 2008. The use of commercially available personal UVmeters does cause less safe tanning habits: A randomized-controlled trial. Photochem. Photobiol., 84: 758-763.

DEN OUTER PN, SLAPER H \& TAX RB. 2005. UV radiation in the Netherlands: assessing long-term variability and trends in relation to ozone and clouds. J. Geophys. Res., 110: D02203, doi:10.1029/2004JD004824.

DIFFEY B. 2006. Do we need a revised public health policy on sun exposure? Br. J. Dermatol., 154: 1046-1051.

DOBBINSON SJ, WAKEFIELD MA, JAMSEN KM, HERD NL, SPITTAL MJ, LIPSCOMB JE \& HILL DJ. 2008. Weekend sun protection and sunburn in Australia. Am. J. Prev. Med., 34: 94-101.

DOWNHAM II TF. 1998. The shadow rule: a simple method for sun protection. Southern Medical Journal, 91: 619-623.

GILLIE 0. 2006. A new government policy is needed for sunlight and vitamin D. Br. J. Dermatol., 154: 1052-1061.

GODAR DE. 2005. UV doses worldwide. Photochem. Photobiol., 81: 736-749.

HALLOWAY L. 1992. Atmospheric sun protection factor on clear days: its observed dependence on solar zenith angle and its relevance to the shadow rule for sun protection. Photochem. Photobiol., 56: 229-234.

HERMAN JR, LARKO D, CELARIER E \& ZIEMKE J. 2001. Changes in the Earth's reflectivity from the surface, clouds, and aerosols. J. Geophys. Res., 106: 5353-5368.

HSU NC, HERMAN JR, TORRES 0, HOLBEN BN, TANRE D, ECK TF, SMIRNOV A, CHATENET B \& LAVENU F. 1999. Comparisons of the TOMS aerosol index with sun-photometer aerosol optical thickness: Results and applications. J. Geophys. Res., 104: 6269-6279.

HÜLSEN G \& GRÖBNER J. 2007. Characterization and calibration of ultraviolet broadband radiometers measuring erythemally weighted irradiance. Appl. Opt., 46: 5877-5886.

KULLVANIJAYA P \& LIM HW. 2005. Photoprotection. J. Am. Acad. Dermatol., 52: 937-958.
LAUTENSCHLAGER S, WULF HC \& PITTELKOW MR. 2007. Photoprotection. Lancet, 370: 528-537.

LONG CS, MILLER AJ, LEE H.-T, WILD JD, PRZYWART RC \& HUFFORD D. 1996. Ultraviolet index forecasts issued by the National Weather Service. Bull. Am. Meteorol. Soc., 77: 729-748.

MCKENZIE RL, AUCAMP PJ, BAIS AF, BJÖRN LO \& ILYAS M. 2007. Changes in biologically-active ultraviolet radiation reaching the Earth's surface. Photochem. Photobiol. Sci., 6: 218-231.

McKINLAY AF \& DIFFEY BL. 1987. A reference action spectrum for ultraviolet induced erythema in human skin. CIE J., 6: 17-22.

PALANCAR GG \& TOSELLI BM. 2002. Erythemal ultraviolet irradiance in Córdoba, Argentina. Atmos. Environ., 36: 287-292.

SCHOEBERL MR, DOUGLAS AR, HILSENRATH E, BHARTIA PK, BARNETT J, GILLE J, BEER R, GUNSON M, WATERS J, LEVELT PF \& DECOLA P. 2004. Earth observing system missions benefit atmospheric research. EOS, 85: 177-184.

SILVA AA. 2007. A quarter century of TOMS total column ozone measurements over Brazil. J. Atmos. Solar-Terrestrial Phys., 69: 1447-1458.

SILVA AA. 2008. Medidas de radiação solar ultravioleta em Belo Horizonte e saúde pública. Revista Brasileira de Geofísica, 26: 417-425.

SILVA AA \& GABRICH LLP. 2007. Seasonal Erythemal UV Doses in Belo Horizonte, Brazil. Photochem. Photobiol., 83: 1197-1204.

SILVA AA, MAYRINK FL, FRANÇA JR CR \& COSTA VA. 2008. Redução da taxa de dose eritematosa solar por uma cobertura de altostratus. In: $60^{\mathrm{a}}$ Reunião Anual da SBPC, 2008, Campinas. Anais eletrônicos da $60^{\mathrm{a}}$ Reunião Anual da SBPC. São Paulo: SBPC/UNICAMP.

SLINEY DH \& WENGRAITIS S. 2006. Is a differentiated advice by season and region necessary? Progress in Biophysics and Molecular Biology, 92: 150-160.

TANGPRICHA V, TURNER A, SPINA C, DECASTRO S, CHEN TC \& HOLICK MF. 2004. Tanning is associated with optimal vitamin D status (serum 25-hydroxyvitamin $\mathrm{D}$ concentration) and higher bone mineral density. Am. J. Clin. Nutr., 80: 1645-1649.

WEINSTOCK MA. 2008. The struggle for primary prevention of skin cancer. Am. J. Prev. Med., 34: 171-172.

WHITTEN RC \& PRASAD SS. 1985. Ozone in the free atmosphere. New York: Van Nostrand Reinhold Company Inc., 288 pp.

WHO (World Health Organization). 1994. Ultraviolet Radiation. Environmental Health Criteria 160. Geneva: WH0. 352 pp.

WHO (World Health Organization). 2002. Global Solar UV-Index: a practical guide. Geneva: WHO. 28 pp.

WOLPOWITZ D \& GILCHREST BA. 2006. The vitamin D questions: How much do you need and how should you get it? J. Am. Acad. Dermatol., 54: 301-317. 


\section{NOTE ABOUT THE AUTHOR}

Abel Antônio da Silva. Named SILVA AA in citation. Physicist who obtained a Master's degree in Nuclear Sciences at the Universidade Federal de Minas Gerais and his Ph.D in Space Geophysics at the Instituto Nacional de Pesquisas Espaciais. Nowadays he has worked as a researcher at the Instituto de Estudos Avançados (IEAv) and as a professor at the Pontifícia Universidade Católica de Minas Gerais (PUC Minas) coordinating the Laboratório de Luz Ultravioleta (LLUV, www.dfq.pucminas.br/PUV/index.html). His research is in the following branches of the Space and Nuclear Geophysics: Ionizing and non-ionizing radiation, instrumentation for the measurement of radiation, atmospheric radiation (radon and its offspring, ultraviolet radiation); atmospheric geophysical parameters (ozone, clouds and aerosols). 